\title{
Auranofin radiosensitizes tumor cells through targeting thioredoxin reductase and resulting overproduction of reactive oxygen species
}

\author{
Hui Wang ${ }^{1}$, Soumaya Bouzakoura ${ }^{1}$, Sven de Mey ${ }^{1}$, Heng Jiang ${ }^{1}$, Kalun Law ${ }^{1}$, Inès \\ Dufait $^{1,2}$, Cyril Corbet ${ }^{3}$, Valeri Verovski ${ }^{1}$, Thierry Gevaert ${ }^{1}$, Olivier Feron ${ }^{3}$, Dirk Van \\ den Berge ${ }^{1}$, Guy Storme ${ }^{1}$, Mark De Ridder ${ }^{1}$ \\ ${ }^{1}$ Department of Radiotherapy, Universitair Ziekenhuis Brussel, Vrije Universiteit Brussel, Brussels, Belgium \\ ${ }^{2}$ Laboratory of Molecular and Cellular Therapy, Vrije Universiteit Brussel, Brussels, Belgium \\ ${ }^{3}$ Pole of Pharmacology and Therapeutics (FATH), Institut de Recherche Expérimentale et Clinique (IREC), Université \\ Catholique de Louvain, Brussels, Belgium
}

Correspondence to: Mark De Ridder, email: mark.deridder@uzbrussel.be

Keywords: auranofin, radiosensitization, ROS, thioredoxin reductase, buthionine sulfoximine

Received: September 30, $2016 \quad$ Accepted: March 01, $2017 \quad$ Published: March 10, 2017

Copyright: Wang et al. This is an open-access article distributed under the terms of the Creative Commons Attribution License (CC-BY), which permits unrestricted use, distribution, and reproduction in any medium, provided the original author and source are credited.

\section{ABSTRACT}

Auranofin (AF) is an anti-arthritic drug considered for combined chemotherapy due to its ability to impair the redox homeostasis in tumor cells. In this study, we asked whether AF may in addition radiosensitize tumor cells by targeting thioredoxin reductase (TrXR), a critical enzyme in the antioxidant defense system operating through the reductive protein thioredoxin. Our principal findings in murine 4T1 and EMT6 tumor cells are that AF at 3-10 $\mu \mathrm{M}$ is a potent radiosensitizer in vitro, and that at least two mechanisms are involved in TrxR-mediated radiosensitization. The first one is linked to an oxidative stress, as scavenging of reactive oxygen species (ROS) by $\mathrm{N}$-acetyl cysteine counteracted radiosensitization. We also observed a decrease in mitochondrial oxygen consumption with spared oxygen acting as a radiosensitizer under hypoxic conditions. Overall, radiosensitization was accompanied by ROS overproduction, mitochondrial dysfunction, DNA damage and apoptosis, a common mechanism underlying both cytotoxic and antitumor effects of AF. In tumor-bearing mice, a simultaneous disruption of the thioredoxin and glutathione systems by the combination of AF and buthionine sulfoximine was shown to significantly improve tumor radioresponse. In conclusion, our findings illuminate TrxR in cancer cells as an exploitable radiobiological target and warrant further validation of AF in combination with radiotherapy.

\section{INTRODUCTION}

The role of reactive oxygen species (ROS) in tumor biology and therapy is currently evolving in two directions. First, ROS clearly sustain tumor progression and the acquisition of chemo- and radioresistance, which are conferred by activation of the antioxidant defense systems that allows tumor cells to proliferate under chronic oxidative stress [1]. Indeed, the level of glutathione (GSH) and the reductive protein thioredoxin (Trx), which maintain the redox homeostasis by eliminating ROS, is frequently increased in human malignancies and linked to poor prognosis [2,3]. Given an elevated intrinsic ability of tumor cells to deal with oxidative damage, the antioxidant approach based on dedicated ROS scavengers, like $\mathrm{N}$-acetyl cysteine (NAC) and mitoTEMPO, has so far not found a place in clinical practice yet suggests interesting possibilities to prevent tumor metastasis [4]. On the other hand, the overproduction (rather than scavenging) of ROS is known to kill tumor cells, a mechanism behind the antitumor effect of mitomycin $\mathrm{C}$, doxorubicin and ionizing radiation $[5,6]$. The latter pro-oxidant strategy is now under intensive development with a focus on gamma-glutamyl cysteine synthase ( $\gamma$-GCS) and Trx reductase (TrxR), as these enzymes are critical in the biosynthesis of GSH and Trx and thus represent promising cancer targets [1].

GSH forms the main intracellular component involved in a redox balance and is essential for cell 
proliferation and cell cycle progression [7]. In addition, GSH determines the storage of intracellular cysteine and eventually regulates the functional status of redox sensitive and cysteine-dependent transcription factors, such as $\mathrm{NF}-\kappa \mathrm{B}$, relevant to both inflammation and apoptosis. Therefore, major efforts in the past have been already aimed at depleting GSH by buthionine sulfoximine (BSO), a potent irreversible inhibitor of $\gamma$-GCS $[1,8]$. This approach appeared to be efficient in sensitizing tumor cells to several chemotherapeutic drugs and radiation $[9,10]$, and its combination with melphalan is now under clinical investigation (https:/clinicaltrials.gov/ct2/show/ NCT00005835).

The history of TrxR is linked to the anti-arthritic drug auranofin (AF), a gold complex with oxidative state (I), which can elicit strong cytotoxicity against tumor cells through the overproduction of ROS that in turn triggers the apoptotic pathway [11-16]. The primary molecular targets of AF are described to be mitochondrial and (to a lesser extent) cytoplasmic TrxR [17], although other mechanisms at the level of proteasome may also contribute to apoptosis [18]. An intriguing finding is that AF may overcome cisplatin resistance, since it impairs mitochondria rather than DNA [19]. Overall, despite being an established antiinflammatory drug, AF seems to offer great promise in the context of pro-oxidant cancer therapy, and is considered for the combined modality treatment of leukemia (https:// clinicaltrials.gov/ct2/show/NCT01419691), lung cancer (https://clinicaltrials.gov/ct2/show/NCT01737502) and epithelial ovarian cancer (https://clinicaltrials.gov/ct2/ show/NCT01747798).

Recently, the antitumor effects of AF have been explored in more detail in preclinical models since this drug is safe for cancer patients and fits the concept of drug repurposing. AF induced strong cytotoxicity in human chronic leukemia and gastric cancer cells due to a lethal endoplasmic reticulum stress and mitochondrial dysfunction accompanied by ROS overproduction $[11,12]$. This effect could be potentiated by other ROS inducers resulting in an increased apoptosis of tumor cells and translated into a meaningful growth inhibition of tumor xenografts [12]. Next to a direct antitumor effect, AF was able to suppress the outgrowth of pulmonary metastases in a model of human osteosarcoma in nude mice, and the inhibition of metastatic phenotype was explained by ROS-dependent apoptosis [13]. Finally, AF was confirmed to be effective in drug-resistant multiple myeloma and chronic leukemia cells, wherein triggering of apoptosis by alternative ROS-dependent and independent mechanisms have been elucidated in depth $[14,15]$. To the best of our knowledge, only one paper so far showed that AF can enhance the radiation response in tumor cells even though the disruption of antioxidant defense systems is a longstanding concept for radiosensitization [20].

In this study, we examined the radiosensitizing potential of AF in vitro with regard to its plasma concentrations and further validated radiotherapeutic applications in tumor-bearing mice. We found that the inhibition of TrxR and resulting ROS overproduction is the principal mechanism of tumor cell radiosensitization, which could be significantly enhanced by GSH depletion. Therefore, our findings suggest the TrxR/Trx system as a promising radiobiological target and prompt further evaluation of AF for radiosensitizing purposes.

\section{RESULTS}

\section{AF caused apoptosis and cytotoxicity in mouse tumor cells}

Our preclinical models are based mainly on EMT6 and 4T1 mouse mammary carcinoma cell lines and tumors, which have been extensively studied in our lab for hypoxic radiosensitization and immunological profiling [21, 22]. To investigate the cytotoxic properties of AF, EMT6 and $4 \mathrm{~T} 1$ cell cultures were treated for $2 \mathrm{~h}$ and cell viability was determined by MTT and colony formation assays (Figure 1A and 1B). In a short-term (2 days) MTT assay, AF decreased the cell viability in a dose-dependent manner with the $\mathrm{IC}^{50}$ values of 19 and $11 \mu \mathrm{M}$ for 4T1 and EMT6 cells respectively. In a long-term (8 days) clonogenic assay, a survival fraction (SF) of 0.1 was detected at 15 and $17 \mu \mathrm{M}$ respectively, indicating that concentrations below $10 \mu \mathrm{M}$ produce less than $1 \mathrm{log}$ cell kill and are suitable for radiosensitization. To determine whether apoptosis was involved in AF-induced cytotoxicity, the exposed tumor cells were stained with Annexin-V/7-AAD followed by flow cytometry analysis in 4T1 cells (Figure 1C-1D), and in EMT6 cells (Figure 1E and Supplementary Figure 2A). At $10 \mu \mathrm{M}$, the apoptotic rates in 4T1 and EMT6 cells were respectively $46 \%$ and $33 \%$, which mainly reflected late apoptosis in 7-AAD-positive tumor cells. Thus, other than apoptotic death pathways contributed to AF-induced cytotoxicity in EMT6 and 4T1 cells as well.

\section{AF inhibited TrxR and triggered ROS overproduction}

It is well accepted that AF elicits cytotoxicity mainly due to its inhibitory effect on TrxR resulting in an overload ROS $[23,24]$. Therefore, first, we assessed the ability of AF to inhibit TrxR activity in 4T1 and EMT6 cells (Figure 2A). The inhibitory effects in both cell lines were evident above $1 \mu \mathrm{M}$ with a profound inactivation of TrxR at 5-10 $\mu \mathrm{M}$ (Figure 2A). Next, the intracellular redox status was evaluated through ROS generation using the fluorescent probe $\mathrm{CM}-\mathrm{H}^{2} \mathrm{DCFDA}$. As shown in Figure 2B-2D (and Supplementary Figure 2B), ROS production was induced in a dose-dependent manner and was significantly upregulated at $7.5(* p<0.05$ and $* * * p<0.001)$ and $10 \mu \mathrm{M}(* * * * p<0.0001)$ in $4 \mathrm{~T} 1$ and EMT6 cells respectively, according to the shift in 
DCFDA signal. Apparently, the inhibition of TrxR by AF occurs at relatively lower concentrations than those causing a considerable increase in ROS, suggesting that other antioxidative systems (such as GSH) may display compensatory effects. Finally, the importance of ROS production in observed effects was confirmed by using NAC, a thiol-reducing antioxidant agent. Pretreatment of 4T1 and EMT6 cells with NAC for $1 \mathrm{~h}$ at $10 \mathrm{mM}$ effectively attenuated the ROS overproduction caused by AF, as shown in Figure 2B-2D further detailed in Supplementary Figure 2B. In addition, NAC counteracted AF-induced cytotoxicity (data not shown), indicating that ROS production and cytotoxicity are linked.

\section{AF radiosensitized aerobic tumor cells}

The radiosensitizing potential of $\mathrm{AF}$ was examined at concentrations below $10 \mu \mathrm{M}$, which are sub-cytotoxic $(<1 \log$ cell kill, Figure 1B) in 4T1 and EMT6 cells. Based on this, tumor cells were treated with $\mathrm{AF}$ at 2.5, 5, 7.5, and $10 \mu \mathrm{M}$ for $2 \mathrm{~h}$ and subsequently exposed to various radiation doses under aerobic conditions (Figure 3A-3B). In line with an increased ROS production shown in Figure $2 \mathrm{C}-2 \mathrm{D}$, we found a dose-dependent radiosensitization with an enhancement ratio above 2 at 7.5-1 $0 \mu \mathrm{M}$, which showed a synergism of AF and radiation. To confirm the role of ROS in AF-induced radiosensitization (at $6 \mathrm{~Gy}$ ), we again applied

B

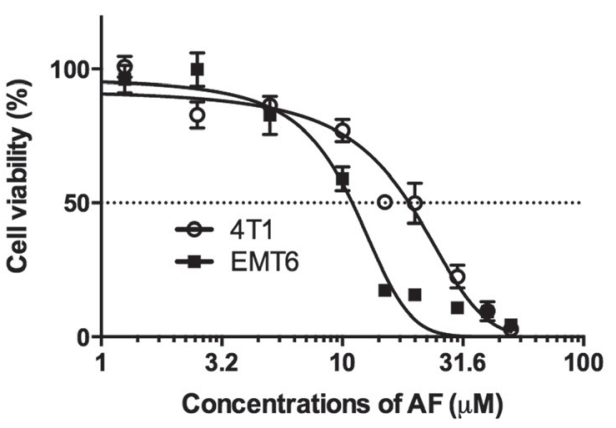

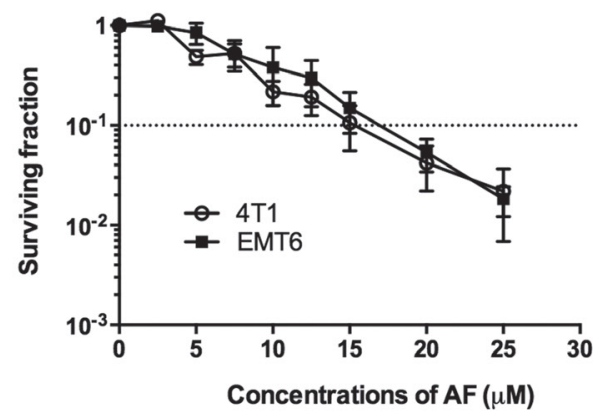

C

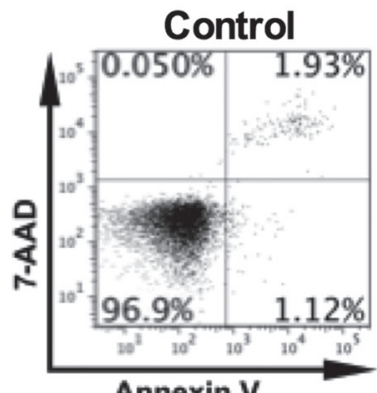

Annexin V

D

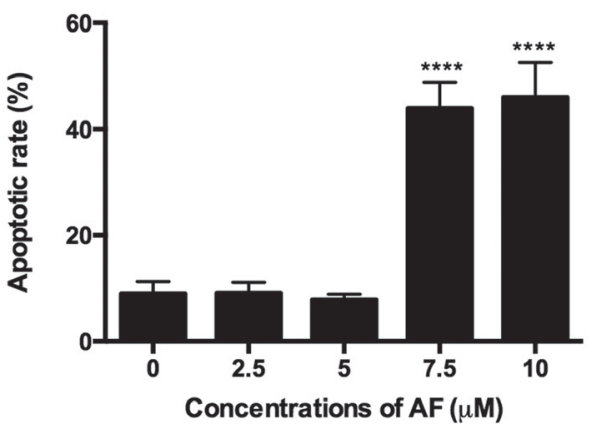

$2.5 \mu \mathrm{M}$
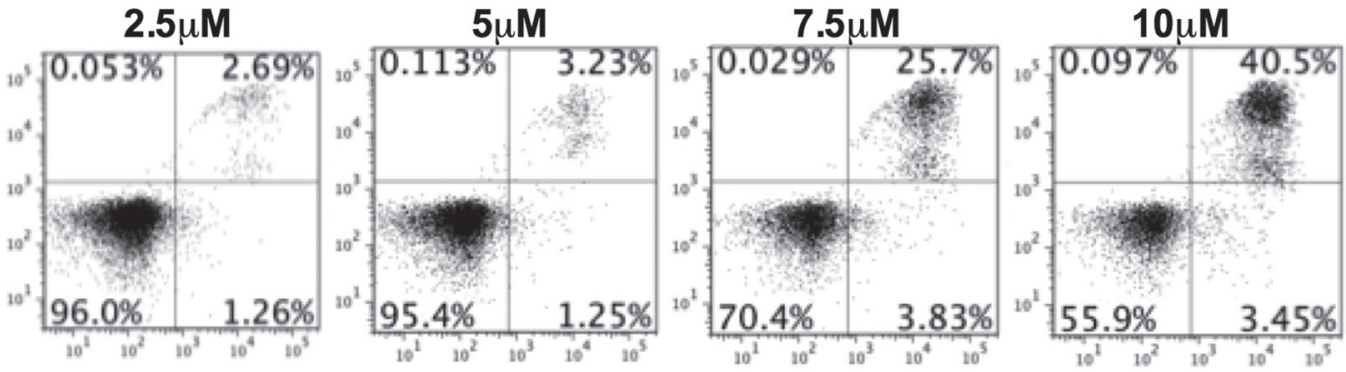

$\mathbf{E}$

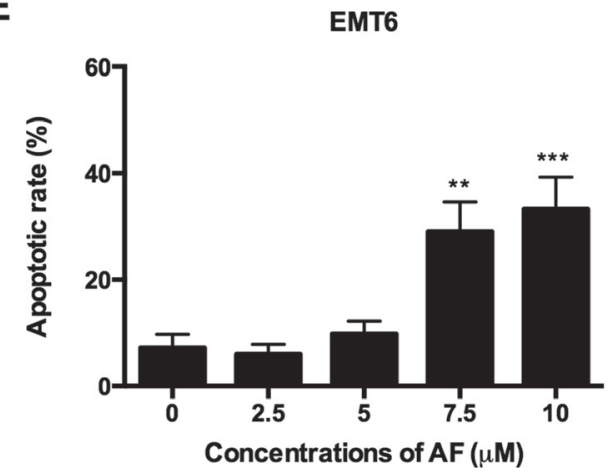

Figure 1: AF caused apoptosis and cytotoxicity in mouse tumor cells. (A) Tumor cells were treated with $\mathrm{AF}$ for $2 \mathrm{~h}$ with indicated concentrations, and one day later analyzed for cell viability by MTT assay. Data are shown as mean $\pm \operatorname{SD}(n=3)$. (B) Following the same treatments, cell viability was analyzed by an 8-day colony formation assay. Data are shown as mean \pm SD $(n=3)$. (C) Representative scatter plots of apoptosis in 4T1 cells, after AnnexinV/7-AAD staining and assessment by flow cytometry. (D) Summarized data on AF-induced apoptosis in 4T1 and (E) EMT6 tumor cells. Data are shown as mean \pm SD $(n \geq 3)$. One-way ANOVA with Bonferonni's multiple comparison test was used to calculate statistics: $* p<0.05, * * p<0.01, * * * p<0.001, * * * * p<0.0001$. 
NAC pretreatment that fully reversed radiosensitization in both 4T1 and EMT6 cells (Figure 3C-3D). Since AF is known to induce ROS-mediated DNA damage, a fundamental mechanism behind radiation-induced cell death, we next examined double-strand DNA breaks by quantifying the phosphorylation status of $\gamma \mathrm{H} 2 \mathrm{AX}$. Radiation ( $8 \mathrm{~Gy})$ or $\mathrm{AF}(7.5 \mu \mathrm{M})$ alone increased the number of $\gamma \mathrm{H} 2 \mathrm{AX}$ foci, which were suppressed by NAC in both cell lines (Figure 3E-3F). Combined treatment displayed an additive effect and increased DNA damage by more than 7-times compared with control $(* * p<0.01, * * * p<0.001$ and $* * * * p<0.0001)$. Taken together, these data indicate a mechanistic link between radiosensitization, DNA damage and ROS overproduction induced by AF through TrxR inactivation.

\section{AF radiosensitized hypoxic tumor cells}

Since tumor hypoxia is known to be radioprotective and causes therapeutic failure, we assessed the radiosensitizing potential of $\mathrm{AF}$ in a tissue-mimetic culture system (TMCS), a metabolic hypoxia model, described in detail by our laboratory in previous studies [22]. First, in murine 4T1 and EMT6 tumor cells, we observed an impaired hypoxic radiosensitivity when compared with aerobic survival curves. Indeed, a $1 \mathrm{log}$ cell kill $(\mathrm{SF}=0.1)$ in hypoxia was achieved with 12.5 and 11 Gy in 4T1 and EMT6 cells (Figure 4A-4B), while under aerobic conditions the same effect was observed at 7 and 6.6 Gy (Figure 3A-3B). Next, a clear AF-induced radiosensitization was observed at 7.5-1 $0 \mu \mathrm{M}$ with an enhancement ratio up to 2.5 and 1.8 for 4T1 and EMT6 cells respectively, pointing to a superior effect in more radioresistant 4T1 cells (Figure 4A-4B). This effect (at $10 \mu \mathrm{M}$ ) was reversed by the addition of NAC in both cell lines (Figure 4C-4D). Afterwards, we validated the radiosensitizing potential of AF in human HCT116 colorectal cancer cells. Under hypoxic conditions, AF induced a dose-dependent radiosensitization with an up to 2.1-fold enhanced radioresponse after exposure to $10 \mu \mathrm{M}$ AF (Supplementary Figure 3A). Similar to aerobic tumor cells, AF induced radiosensitization was counteracted by
A

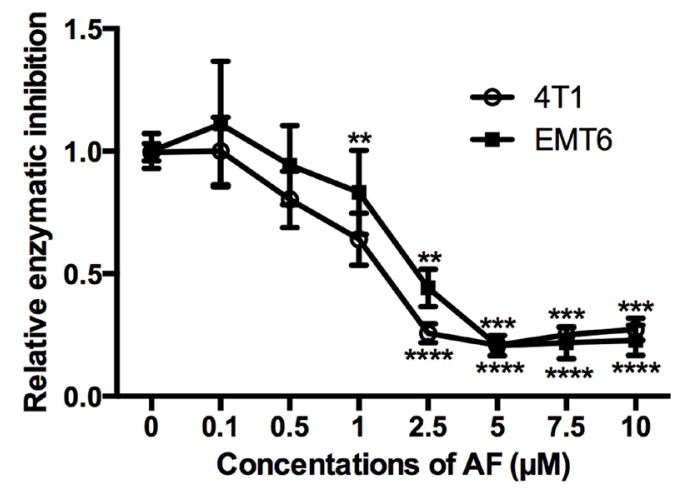

C

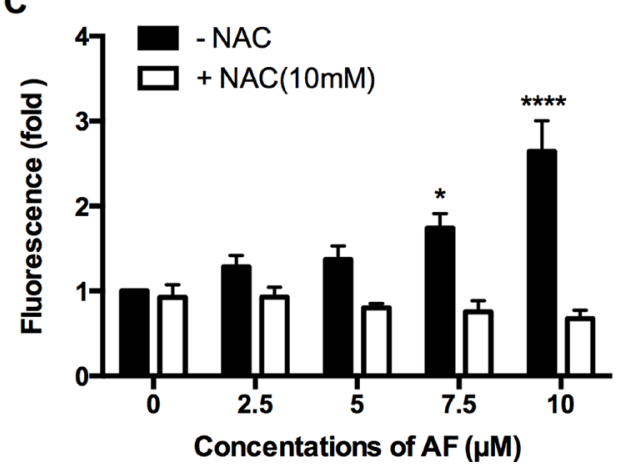

$2.5 \mu \mathrm{M}$

B

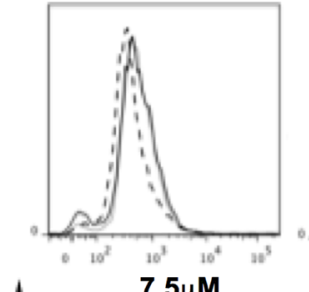

$7.5 \mu \mathrm{M}$

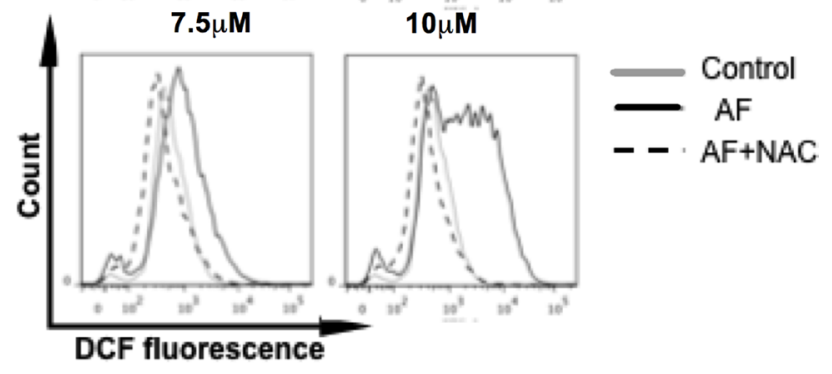

D

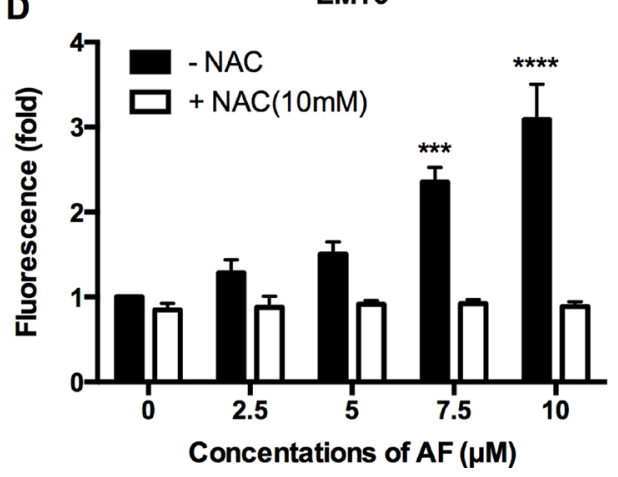

Figure 2: AF inhibited TrxR and triggered ROS overproduction in tumor cells. (A) TrxR activity was measured by commercial kit and all values were normalized to untreated controls. Data are shown as mean $\pm \operatorname{SD}(n \geq 3)$. (B) Representative histogram of intracellular ROS in 4T1 cells, as analyzed by flow cytometry using the CM-H ${ }^{2}$ DCFDA probe. (C-D) Summarized data on ROS production in 4T1 and EMT6 cells pretreated with the ROS scavenger NAC $(10 \mathrm{mM})$ prior to AF. Data are shown as mean \pm SD $(n=3)$. One-way ANOVA with Bonferonni's multiple comparison test was used to calculate statistics: ${ }^{*} p<0.05,{ }^{* *} p<0.01, * * * p<0.001,{ }^{* * * *} p<0.0001$. 
NAC at $10 \mathrm{mM}$ while NAC on its own did not modulate radioresponse in hypoxia (Supplementary Figure 3B). Overall, NAC pretreatment (without AF) did not exert any impact on radioresponse in all tumor cell lines including 4T1, EMT6 and HCT116, as further detailed in Supplementary Figure 4. At this point, we compared the radiosensitivity profiles of EMT6 versus 4T1 tumor cells (Figures 3-4), and concluded that the latter model displays a trend to decreased intrinsic radiosensitivity. Therefore, the next steps in our study have been limited to 4T1 model
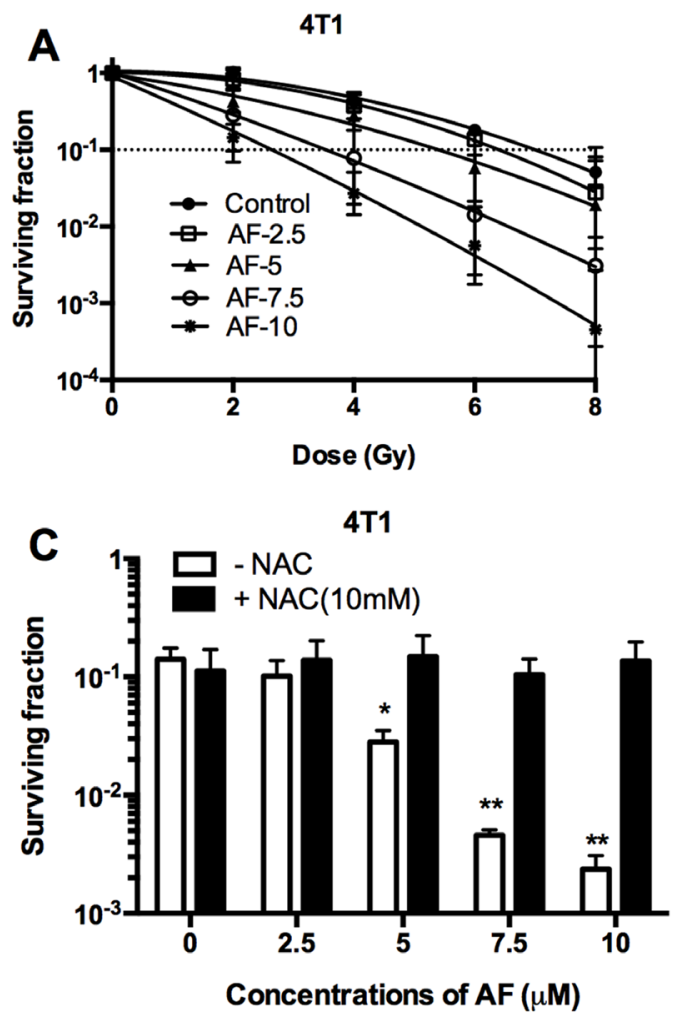

$\mathbf{E}$ 4T1

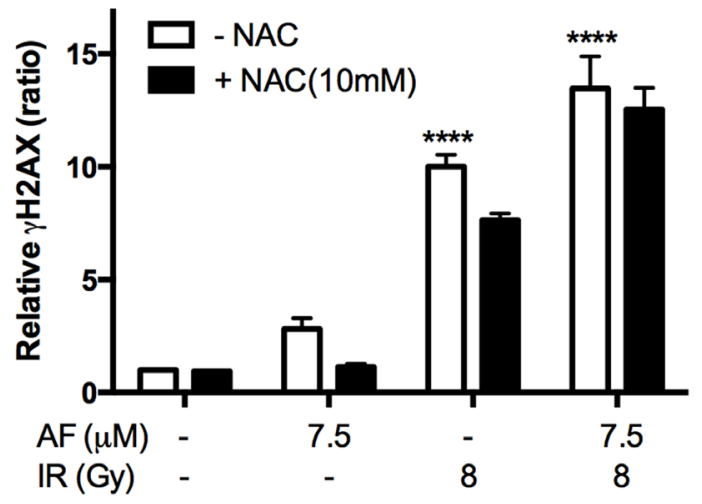

assuming that these tumor cells feature a more efficient antioxidant system - an optimal target for AF and BSO.

\section{AF induced mitochondrial dysfunction in 4T1 tumor cells}

As ROS generation is a by-pass of mitochondrial bioenergetics, the respiratory status of tumor cells has been further dissected in a Seahorse analyzer using a sequence of specific inhibitors. AF significantly decreased
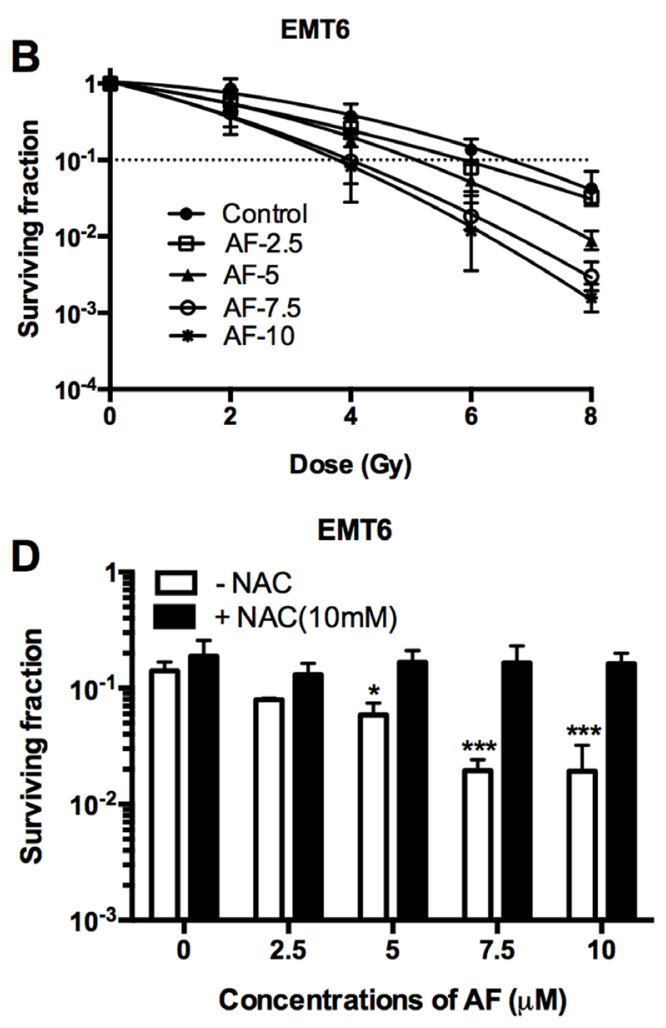

$\mathbf{F}$

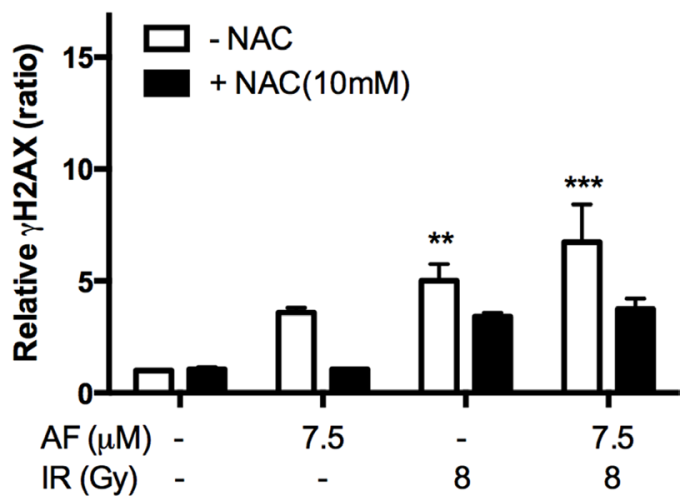

Figure 3: AF radiosensitized aerobic tumor cells and enhanced radiation induced DNA damage. 4T1 and EMT6 cells were treated with AF for $2 \mathrm{~h}$ at indicated concentrations, while NAC $(10 \mathrm{mM})$ was added $1 \mathrm{~h}$ prior and during treatment. (A-B) The radiosensitizing effect of AF was assessed by colony formation assay. Data are shown as mean $\pm \mathrm{SD}(n=3)$. (C-D) Counteracting effect of the ROS scavenger NAC at 6 Gy. (E-F) Double-strand DNA breaks were analyzed by flow cytometry using the $\gamma \mathrm{H} 2 \mathrm{AX}$-based foci measurements. Data are shown as mean $\pm \mathrm{SD}(n \geq 3)$. One-way ANOVA with Bonferonni's multiple comparison test was used to calculate statistics: $* p<0.05, * * p<0.01, * * * p<0.001, * * * p<0.0001$. 
the basal oxygen consumption rate, and in addition the maximal respiratory capacity and ATP output in 4T1 tumor cells $(* * p<0.01, * * * p<0.001$ and $* * * * p<0.0001)$, as illustrated in Figure $5 \mathrm{~A}$ and further summarized in Figure 5B. Overall, the inhibition of oxygen consumption and the resulting sparing of oxygen, a potent radiosensitizer, seem to offer an additional radiosensitizing effect specifically in hypoxia next to the basic mechanism through ROS overproduction. To get more insight into mitochondrial dysfunction induced by AF, we measured the mitochondrial membrane potential $\Delta \Psi \mathrm{m}$, an important parameter of membrane integrity. We anticipated that membrane depolarization would explain an uncoupled oxidative phosphorylation (ATP decline) and resulting apoptosis induced by $\mathrm{AF}$ in 4T1 tumor cells (Figures 5A-5B and $1 C-1 D$ ). As demonstrated in Figure $5 \mathrm{C}-5 \mathrm{D}$ (and Supplementary Figure 2C), exposed tumor cells showed a decreased signal of TMRE, a cell permeable fluorescent dye, which is effectively retained in intact but not damaged mitochondria. We observed a dose-dependent decrease of $\Delta \Psi \mathrm{m}$ induced by AF with $50 \%$ inhibition at $10 \mu \mathrm{M}(* p<0.05)$.

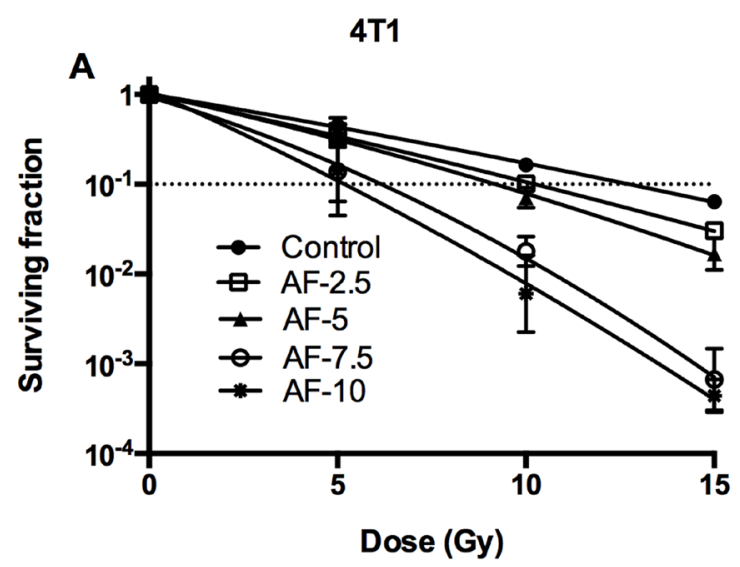

4T1

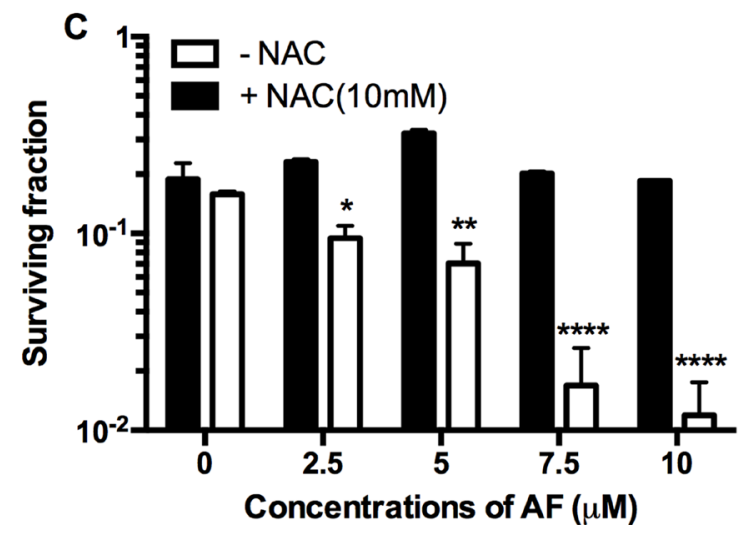

\section{BSO potentiated AF-induced radiosensitization in $4 \mathrm{~T} 1$ tumor cells}

Given that GSH may back-up the deficit of reduced Trx, we asked whether a dual targeting of those systems by AF and BSO may be beneficial in terms of cytotoxicity and radiosensitization. First, we assessed GSH biosynthesis in 4T1 cells, and found a progressive depletion of total GSH caused by BSO at $0.25-3 \mu \mathrm{M}$ $(* * p<0.01$ and $* * * * p<0.0001)$ with a half-decline at $0.5 \mu \mathrm{M}$ (Figure 6A). Next, we examined the effect of combined AF and BSO at non-cytotoxic concentrations of 2.5 and $3 \mu \mathrm{M}$ respectively. Strikingly, this combination displayed significant synergism with a resulting SF of 0.3 $(* * * p<0.001)$, which was abolished by NAC (Figure 6B). Based on these data, similar combinations were applied for radiosensitizing purposes under both aerobic and hypoxic conditions. BSO $(1 \mu \mathrm{M})$ and $\mathrm{AF}(2.5 \mu \mathrm{M})$ alone did not alter radiosensitivity, while their combination enhanced aerobic and hypoxic radioresponse by 1.5 and 1.9 times respectively (Figure 6C-6D). Thus, this combination showed a preferential radiosensitizing effect in hypoxic
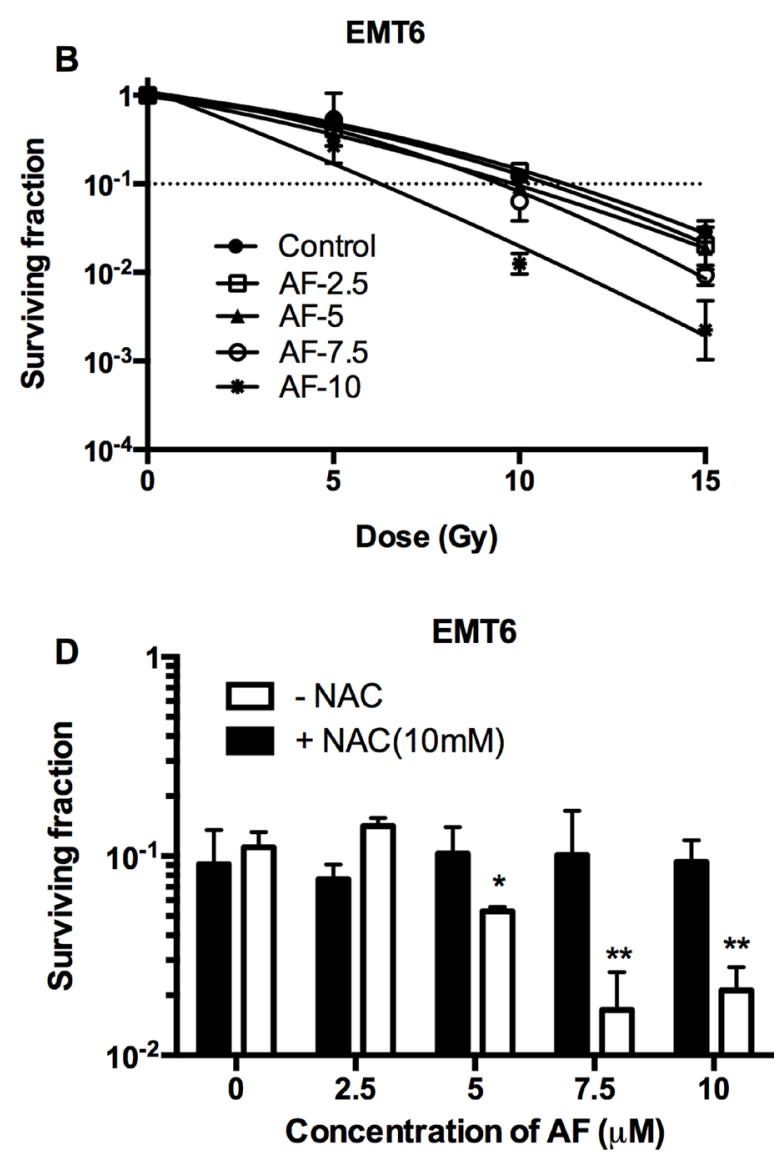

Figure 4: AF radiosensitized hypoxic tumor cells. 4T1 cells were treated with AF for $2 \mathrm{~h}$ at indicated concentrations, while NAC $(10 \mathrm{mM})$ was added $1 \mathrm{~h}$ prior and during treatment. To assess hypoxic radiosensitivity, subconfluent cultures were irradiated in a metabolic hypoxia model TMCS. (A-B) Radiosensitizing effect of AF was assessed by colony formation assay. Data are shown as mean \pm SD $(n=3)$. (C-D) Counteracting effect of the ROS scavenger NAC at $10 \mathrm{~Gy}$. Data are shown as mean \pm SD $(n \geq 3)$. One-way ANOVA with Bonferonni's multiple comparison test was used to calculate statistics: ${ }^{*} p<0.05,{ }^{* *} p<0.01,{ }^{* * *} p<0.001,{ }^{* * * *} p<0.0001$. 
4T1 cells, which displayed a clear radioprotection in the TMCS, our model of metabolic hypoxia. As expected, those synergistic effects were counteracted by NAC (Figure 6E-6F). The observed synergism between AF and $\mathrm{BSO}$ was of particular interest for in vivo applications since the plasma-achievable levels of AF are known to be around $3 \mu \mathrm{M}$, which is on a low side of effective radiosensitizing concentrations according to our data (Figures 3-4).

\section{AF combined with BSO enhanced radioresponse of $4 \mathrm{~T} 1$ tumor}

To validate the in vitro findings, the radiosensitizing effect of AF combined with BSO was evaluated in both 4T1 and EMT6 tumor-bearing mice. The experimental scheme is depicted in Figure 7A. In 4T1 tumor model, radiation alone at 15 Gy delayed tumor growth by 6 days measured at a tumor volume of $1000 \mathrm{~mm}^{3}$ (Figure 7B). AF combined with $\mathrm{BSO}$ enhanced tumor radioresponse resulting in a tumor growth delay of 13 days and thereby significantly increased the medium survival rate (Figure 7B and 7C), while neither of these pharmaceuticals were effective when administered on their own (Figure 7D and 7E). Importantly, BSO (25 mg/kg) and/or AF (3 mg/kg) applied for 10 days were safe and represented the maximal tolerated doses with no significant body weight loss (Figure 7F). In EMT6 tumor model, which is more radiosensitive than $4 \mathrm{~T} 1$, radiation alone at 12 Gy delayed tumor growth by 20 days measured at a tumor volume of $500 \mathrm{~mm}^{3}$ (Figure 8A). AF plus BSO further delayed the tumor growth by 9 days compared with radiation alone (Figure $8 \mathrm{~A}$ ), and this combination once again increased the survival rate of tumor-bearing mice (Figure $8 \mathrm{~B}$ ). Of note, similar to 4T1 tumor model, BSO plus AF treatment did not show notable toxicity in mice, as measured by the body weight loss (Figure 8C). Altogether, our data point to the necessity of dual targeting of the TrxR/GSH systems by the combination of AF and BSO.

\section{DISCUSSION}

In this study we examined the hypothesis that the anti-arthritic drug AF may be repurposed for radiotherapeutic applications and undertook the first step to evaluate its radiosensitizing potential in mouse 4T1 and EMT6 tumor cells. Our fundamental findings are that AF at $3-10 \mu \mathrm{M}$ increases tumor cell radiosensitivity in vitro over 2-fold, and two mechanisms appear to be engaged. The first one is tightly related to an oxidative stress, as the classic scavenger NAC abolished both ROS overproduction and radiosensitization yet by itself did not modulate radioresponse. These divergent properties may be explained by its ability to mitigate radiation-induced DNA damage but not affect the cell kill [25]. The latter result is further corroborated by the very efficient TrxR/GSH anti-oxidant systems in tumor cells that overweigh the scavenging potential of NAC under basal levels of ROS in the absence of AF. Under tumor-modeling hypoxic conditions, we also observed the arrest of oxygen consumption in mitochondria suggesting an alternative effect of AF through spared oxygen, a potent radiosensitizer. The latter mechanism can be detected only in metabolically induced hypoxia, which recently attracted more attention given that the inhibition of mitochondrial respiration rather than an increase in oxygen supply may offer an efficient way to overcome hypoxic radioresistance $[22,26]$. Tumor hypoxia is a recognized negative factor for therapy outcomes, and the ability of AF to reverse metabolic radioresistance suggests the promising possibility to preferentially target poorly oxygenated tumor cells.

It is worthy to stress that the nature of effects so far ascribed to AF, and more generally to gold formulations, is multifaceted and continues to expand. The metallic gold in a form of nanoparticles is non-toxic up to $1000 \mu \mathrm{M}$ and displays radiosensitizing properties due to the secondary low-energy beams (Auger electrons) that amplify radiation-induced DNA damage [27]. Both low toxicity and direct radiosensitization are lost once the gold atom is oxidized to a complex (I), with AF as an example, and further to a more stable complex (III), both of which were broadly screened for cytotoxicity and antitumor effects [28]. AF was reported to inactivate TrxR above $3 \mu \mathrm{M}$ that in part explains strong cytotoxicity against tumor cells, as lack of this redox-critical enzyme results in mitochondrial dysfunction caused by ROS [17].

In line, we found (i) dose-dependent TrxR inhibition, (ii) followed by ROS overproduction and (iii) accompanied by mitochondrial and further DNA damage. This sequence of events caused by AF has been described in many types of tumor cells undergoing apoptosis $[11,12,16]$, which was detected in our model as well yet leaving a space for other (unidentified) death pathways. In our settings, apoptosis was detected above $5 \mu \mathrm{M}$ AF in a threshold-like manner, a phenomenon that seems to be triggered once the level of ROS becomes incompatible with the mitochondrial membrane integrity [29]. Interestingly, AF-induced radiosensitization through TrxR occurs at 1-2 log lower concentrations when compared with that of bio-inert metallic gold operating through photoelectrons [30]. More importantly, our data indicate that AF at plasma relevant levels is exploitable for radiosensitization, a novel mechanism that points to an appealing opportunity of rescaling current clinical trials so far limited to chemotherapeutic goals (https://clinicaltrials. gov/ct2/show/NCT01747798, https:/clinicaltrials.gov/ct2/ show/NCT01737502). Supporting this conclusion, two other gold (I) complexes, namely $\mathrm{Au}(\mathrm{SCN})(\mathrm{PEt}(3))$ and an $\mathrm{Au}(\mathrm{I})$-indole, were reported to possess radiosensitizing properties as well $[31,32]$.

It is essential to acknowledge that ROS-mediated effects are complex and interplay with the multiple 
inflammatory pathways associated with tumor progression, as schematically summarized in Supplementary Figure 1. Briefly, ROS may display both pro- and anti-tumor properties, and on the top we could expect both proand anti-inflammatory effects from AF, considering the history of its use as an anti-arthritic drug [33]. The latter medication was linked to the inhibition of proinflammatory mediators (IL-6, IL- $1 \beta, \mathrm{TNF} \alpha, \mathrm{NF}-\kappa \mathrm{B}$ etc.) and oxidative burst in monocytes and granulocytes respectively [34, 35]. This picture is opposed to a more recent pro-oxidant approach, where drug-induced ROS cause apoptosis/cytotoxicity in tumor cells [1]. It remains to be clarified whether an oxidative stress signature is of prognostic value, while the inflammatory desmoplastic reaction in tumor-associated fibroblasts is known to promote tumorigenesis [36]. In this context, our findings are obviously valid for tumor cells only and should not be projected to the host stromal and immune cells involved in cancer-related inflammation. However, we previously showed that myeloid cells can undergo protumor polarization [37], accompanied by an increased neutrophil-to-lymphocyte ratio and arginase activation [21], in line with the recent literature [38, 39] and the extensive background on the immune landscape in cancer $[40,41]$. Hence, AF might target the myeloid lineage differently from tumor cells and thereby offer still another way to restore tumor radioresponse through immune cells, as we previously proposed for rectal cancer [42].

While this speculative mechanism remains to be explored, our preliminary data suggest that the in vitro radiosensitizing effect of $\mathrm{AF}$, evident in aerobic and hypoxic 4T1 and EMT6 tumor cells, is a probable cause of an improved tumor radioresponse in vivo. This setting was designed with regard to a current consensus on the coordinated role of the $\gamma$-GCS/GSH and TrxR/Trx antioxidant systems in clinical chemo- and radioresistance, as overviewed in detail elsewhere [9, 19, 43]. The $\gamma$-GCS inhibitor BSO is a well-documented chemo- and radiosensitizer in experimental models [10], and in our hands it potentiated the cytotoxic and radiosensitizing effect of AF in vitro. The combination AF plus BSO showed a preferential radiosensitizing effect in hypoxic
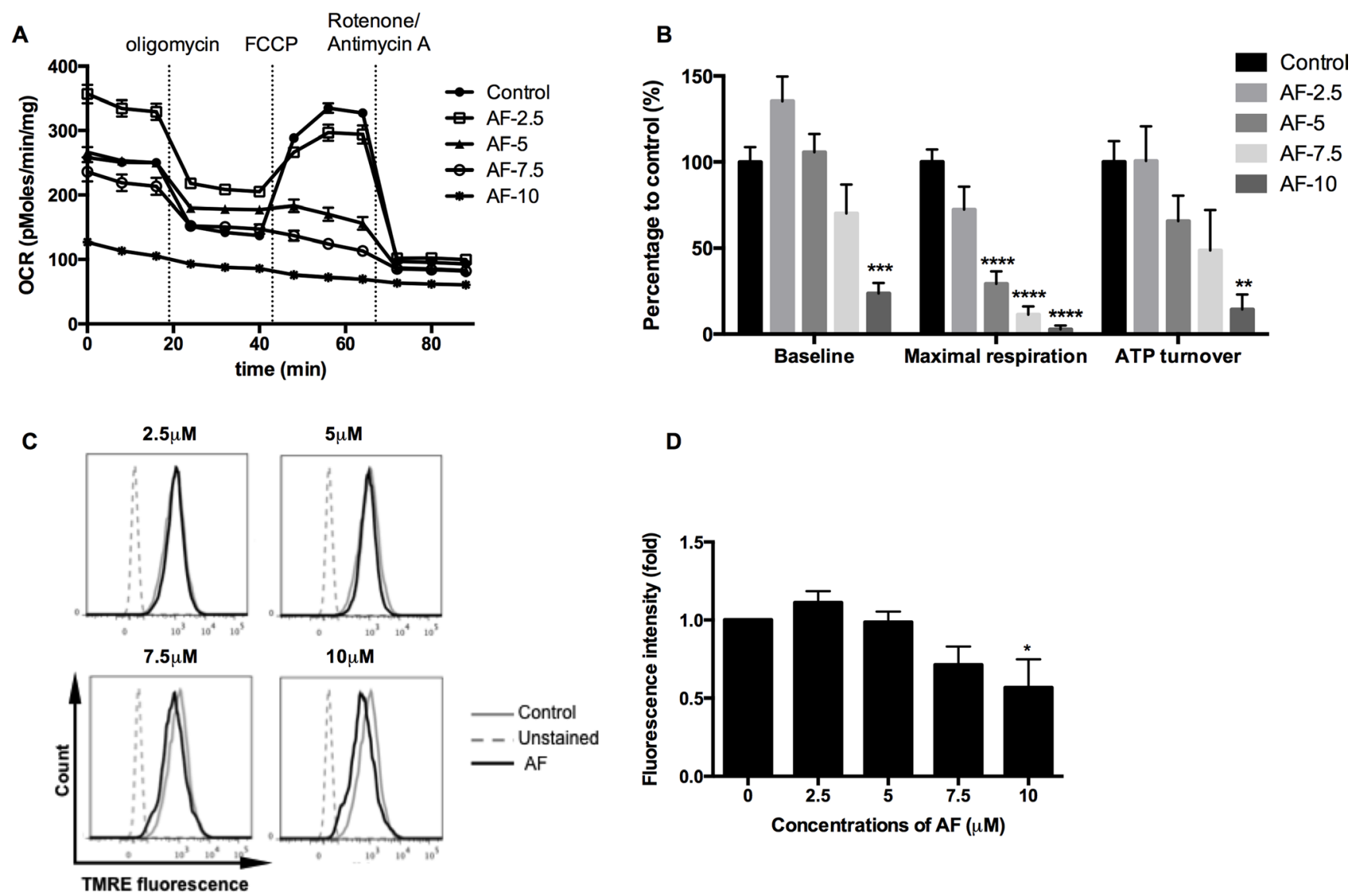

D

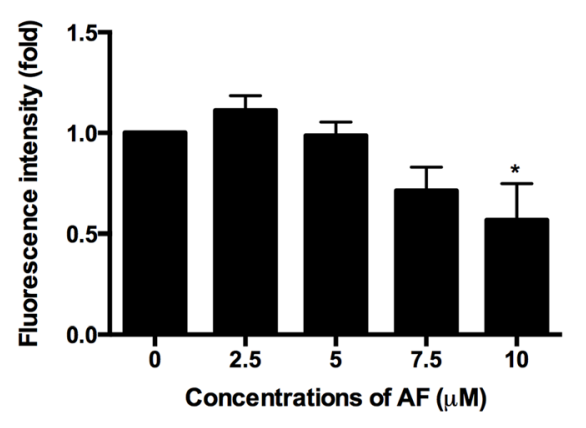

Figure 5: AF induced mitochondrial dysfunction in tumor cells. 4T1 cells were treated with AF for $2 \mathrm{~h}$ at indicated concentrations and the respiratory profiles were examined by a Seahorse Analyzer. (A) Dissection of respiratory rates by the sequential injection of oligomycin, FCCP, rotenone and antimycin A at indicated time points. (B) Summarized data on the baseline respiratory rate, maximum respiratory capacity and ATP turnover. Data are shown as mean $\pm \mathrm{SD}(n=5)$. (C-D) Representative measurements of $\Delta \Psi \mathrm{m}$ in $4 \mathrm{~T} 1$ cells by flow cytometry and summarized data on membrane potential. Data are shown as mean $\pm \mathrm{SD}(n=3)$. One-way ANOVA with Bonferonni's multiple comparison test was used to calculate statistics: $* p<0.05, * * p<0.01, * * * p<0.001, * * * * p<0.0001$. 
tumor cells, which featured an impaired radioresponse in the TMCS, our model of metabolic hypoxia. In mice, their simultaneous administration enhanced radioresponse in EMT6 and 4T1 mammary carcinomas, in line with a very recent report in a MDA-MB-231 breast cancer model [20]. We concluded that the combination of AF and BSO could be a promising radiosensitizing strategy justified in view of them being ready-to-use pharmaceuticals for clinical evaluation.
In contrast to some other reports, we were not able to detect the antitumor effect induced by AF and BSO alone but confirmed low toxicity associated with their chronic use. A plausible explanation is that radiosensitization may occur at lower sub-cytotoxic drug levels $(<1 \log$ cell kill) than those required for the direct inhibition of fast growing tumors, therefore pointing to a synergistic interaction with irradiation. Clearly, a plasma achievable level of $3 \mu \mathrm{M}$, known for AF [44], is a limiting factor of cytotoxicity and
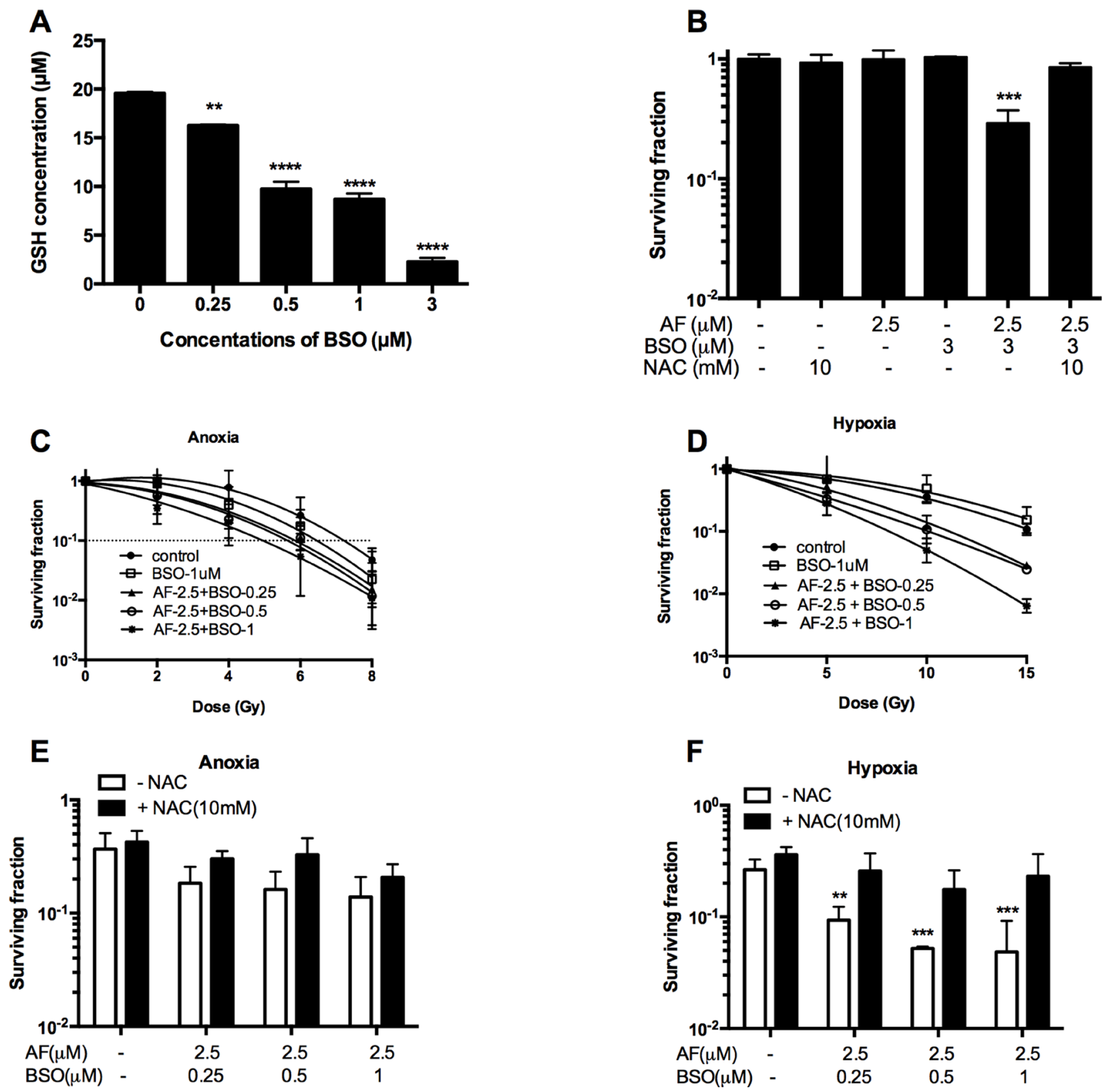

Figure 6: BSO potentiated AF-induced radiosensitization in tumor cells. 4T1 cells were exposed to AF and/or BSO at indicated concentrations for 2 and $16 \mathrm{~h}$ respectively. (A) Depletion of glutathione by BSO in 4T1 cells. Data are shown as mean \pm SD $(n \geq 3)$. (B) Synergistic cytotoxicity of AF combined with BSO applied at non-cytotoxic concentrations. Data are shown as mean \pm SD $(n \geq 3)$. (C-D) Aerobic and hypoxic radiosensitization by AF combined with BSO, as measured by colony formation assay. Data are shown as mean $\pm \mathrm{SD}(n=3)$. ( $\mathbf{E}-\mathbf{F})$ Counteracting effect of the ROS scavenger NAC under aerobic and hypoxic conditions respectively. Data are shown as mean $\pm \mathrm{SD}(n=3)$. One-way ANOVA with Bonferonni's multiple comparison test was used to calculate statistics: ${ }^{*} p<0.05, * * p<0.01$, $* * * p<0.001, * * * * p<0.0001$. 
radiosensitization in vivo, which are below the observed effects in cell cultures rescaled to $5-10 \mu \mathrm{M}$. Our preclinical settings also suffer from some limitations due to the intramuscular tumor site, therefore lacking the physiological microenvironment in the mammary gland. However, radiotherapeutic applications in mice require a practical way to immobilize the bulky tumors precisely within the irradiation field, and are generally based on non-orthotopic implantations [20]. On the other hand, our pharmacological treatments do reflect clinical trials, where AF is administered chronically at safe maximal tolerated doses.

Likewise, recent preclinical studies highlighted the chemotherapeutic importance of knocking down the antioxidant cellular defense by AF, and described an impressive list of divergent ROS-mediated mechanisms, which suppressed the growth of local tumors [11, 12] and metastasis [13] or reversed chemoresistance [19]. Along with improved radiation responses, AF sensitized breast cancer stem cells, and in combination with BSO decreased cell migration and invasion [20]. Of note, inhibition of TrxR by curcumin and 1, 2, 5-selenadiazole showed a comparable array of antitumor effects including radiosensitization [32, 45-47], while the disruption of GSH pathways by genistein and gadolinium (III) texaphyrin resulted in ROS-mediated radiosensitization $[48,49]$. Compelling evidence also suggests that the abundant GSH pool is an important backup to keep Trx reduced, and therefore a dual targeting of the GSH/Trx antioxidant systems is required $[43,50]$.

The next logical development is to apply a triple inhibition of GSH/Trx/Nrf2, where the latter mediator is responsible for maintaining the anti-oxidant system in a reduced state [51]. Blocking the glycolysis and pentose cycle pathways may also interrupt GSH/Trx-dependent cellular defense, while NAC reverses an amplified clonogenic cell death triggered by ROS [52]. Both Trx and GSH are currently recognized as key targets in chemo/ radiosensitizing strategies in line with our data, while a single TrxR inactivation may not be always enough to achieve meaningful effects. Indeed, genetic knockingdown of TrxR by siRNA appears to be short of efficiency to inhibit its enzymatic activity or to provoke ROS overproduction, likely due to high TrxR abundance at translational and transcriptional levels fostered by GSH $[51,52]$. Overall, the multi-layered anti-oxidant system in tumor cells prompts a multi-targeted approach to deal with clinical chemo/radioresistance.

The recent progress in cancer radiotherapy is based on the stepwise implementation of image-guided and intensity-modulated radiation beams that deliver a shaped dose distribution tailored to tumor anatomy [53]. However, up to $30 \%$ of locally advanced cancers show unsatisfactory down-staging even after applying a simultaneous integrated boost that nowadays represents the most intensified radiation approach to improve local control [54]. Further dose escalation would compromise clinical safety, and thus overcoming radioresistance by available pharmaceuticals is an urgent need and necessity in order to address poor outcome in high-risk patients. Our preclinical 4T1 and EMT6 tumor models suggest that an increased local radioresponse is feasible, once the antioxidant defense systems are targeted by specific inhibitors at the cost of marginal if any adverse effects. As outlined above (Supplementary Figure 1), our understanding of inflammatory and ROS-mediated pathways in cancer is evolving, and opens novel possibilities to revisit

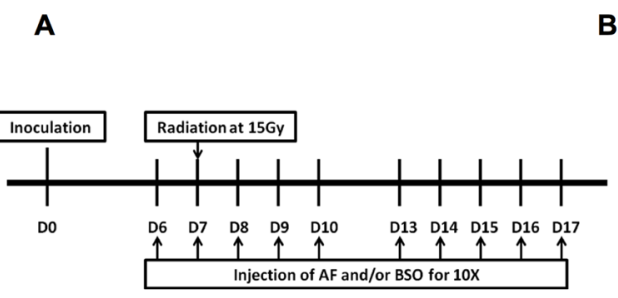

D

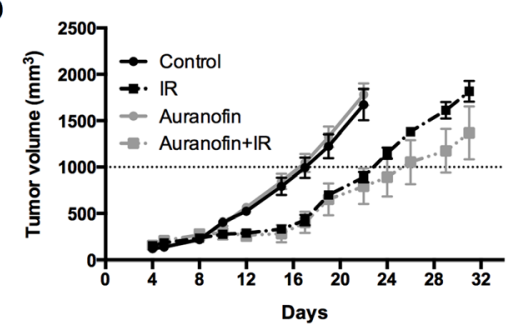

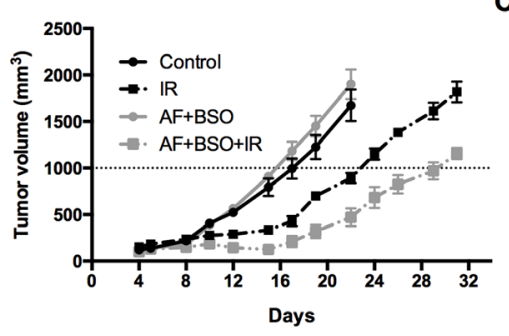

E

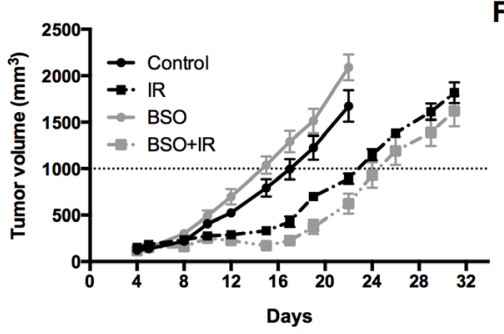

F
C
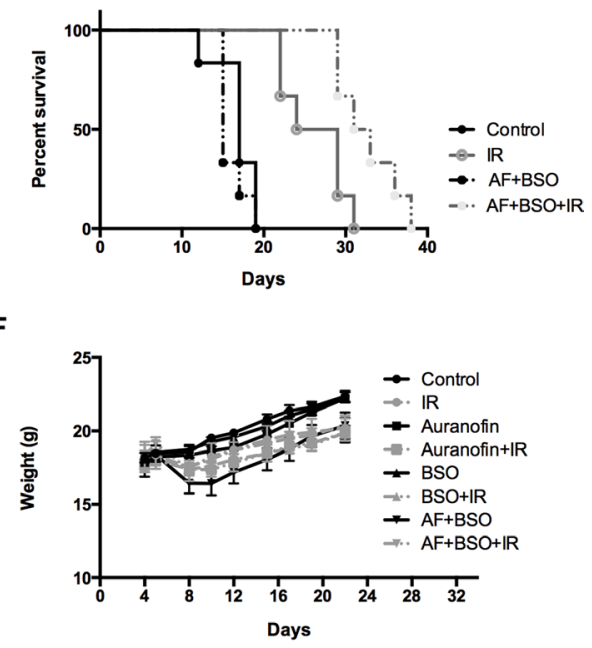

Figure 7: AF combined with BSO enhanced the radioresponse of $4 \mathrm{~T} 1$ tumor in Balb/c mice. AF and BSO were administered subcutaneously for 10 times to tumor-bearing mice, and single dose radiation at $15 \mathrm{~Gy}$ was delivered on the second day of treatment. (A) Experimental scheme depicting used treatment protocols. (B) Tumor growth in mice treated with radiation and the combination of AF $(3 \mathrm{mg} / \mathrm{kg})$ and BSO $(25 \mathrm{mg} / \mathrm{kg})$. (C) Survival curves of mice euthanized at a diameter of $15 \mathrm{~mm}$. (D) Tumor growth in mice treated with radiation and AF only. (E) Tumor growth in mice treated with radiation and BSO only. (F) Assessment of toxicity by body weight loss. 
established drugs with yet uncovered radiosensitizing properties. With this concept in mind, our research program at Radiotherapy Department (UZ Brussels) is making major efforts to re-examine metformin (manuscript in preparation) and AF for radiotherapeutic applications, and the present set of data emphasizes a novel way to exploit the known molecular target TrxR for radiosensitizing purposes. The next pre-clinical steps could be validation of AF-induced radiosensitization in other tumor models and for fractionated radiation.

In conclusion, the anti-arthritic drug AF reveals radiosensitizing properties through targeting TrxR and resulting ROS overproduction, a common mechanism conferring its cytotoxic, antitumor and chemosensitizing effects. Our findings illuminate the redox TrxR/Trx system in cancer cells as an exploitable radiobiological target, and warrant further experimental and clinical approval for AF in combination with radiotherapy.

\section{MATERIALS AND METHODS}

\section{Cell lines and chemicals}

Murine mammary adenocarcinoma EMT-6 cells were kindly provided by Dr. Edith Lord (University of Rochester, Cancer Center, New York) and 4T1 cells were obtained from ATCC (American Type Culture Collection) respectively. All experiments were performed in RPMI 1640 medium (Thermo Fisher, Belgium) supplemented with $10 \%$ bovine calf serum (Greiner Bio-one, Belgium). Chemicals were obtained from Sigma-Aldrich (Antwerp, Belgium) unless otherwise stated.

\section{Treatments}

EMT-6 and 4T1 cultures were grown to confluence and treated with AF (2 h) and/or BSO (16 h) at indicated concentrations. The ROS scavenger $\mathrm{N}$-acetyl cysteine (NAC) was added at $10 \mathrm{mM}$ to cultures both $1 \mathrm{~h}$ prior and during treatment with AF. Afterwards, cultures were used for further analysis as described below.

\section{Cytotoxicity and MTT assay}

A total of 5000 cells were plated in $100 \mu \mathrm{l}$ medium in 96-well plates and allowed to adhere for $24 \mathrm{~h}$. AF was added at indicated concentrations for $2 \mathrm{~h}$, and cultures were rinsed with fresh medium and re-incubated for additional $24 \mathrm{~h}$. Next, $10 \mu \mathrm{l}$ of the MTT reagent $(5 \mathrm{mg} / \mathrm{ml})$ was added for $3 \mathrm{~h}$, and $150 \mu \mathrm{l}$ of DMSO was admixed to dissolve the formazan crystals. Absorbance was measured at a wavelength of $540 \mathrm{~nm}$ by using a spectrophotometer

\section{A}
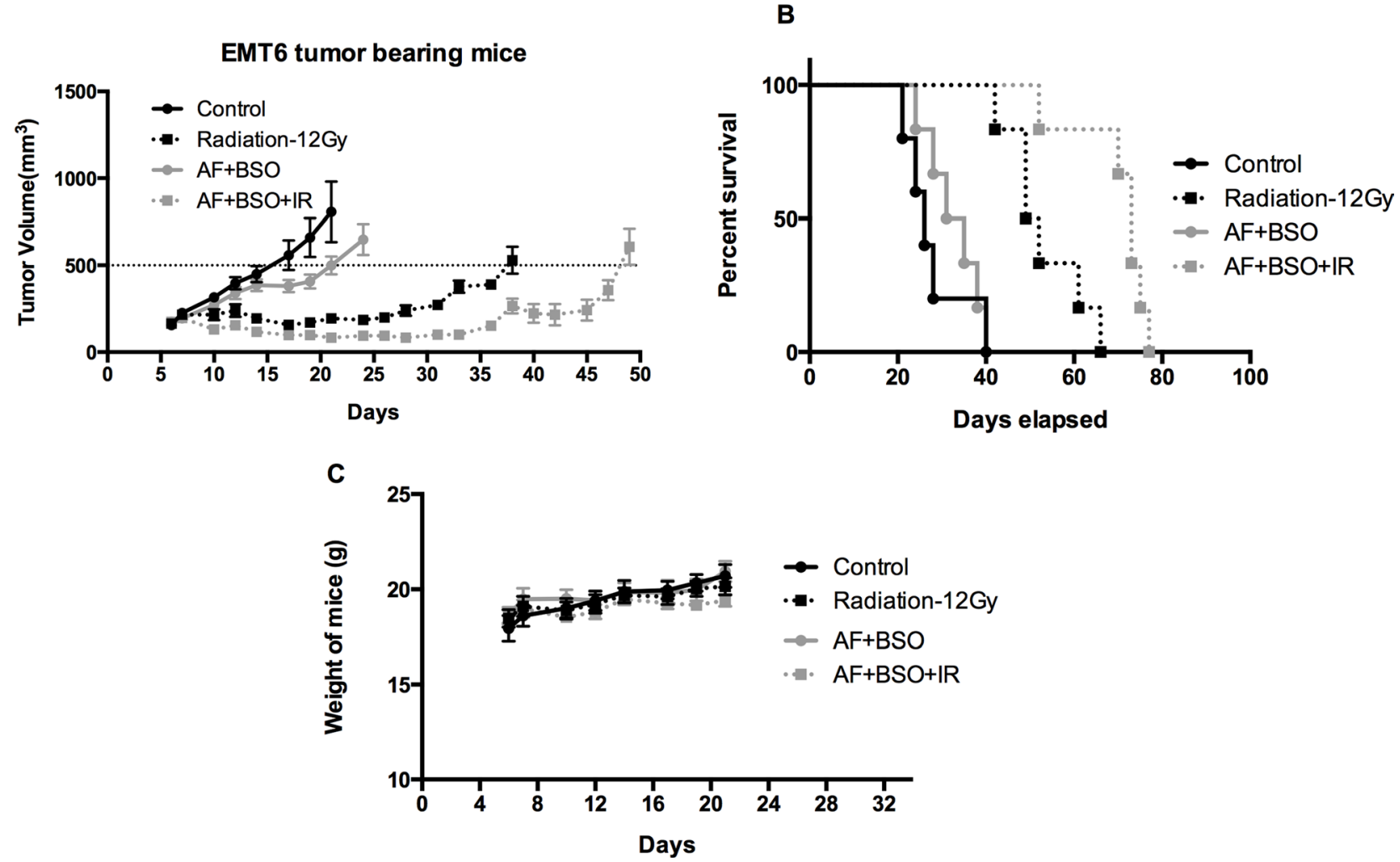

Figure 8: AF combined with BSO enhanced the radioresponse of EMT6 tumor in Balb/c mice. AF and BSO were administered as above in 4T1 tumor model, and single dose radiation at 12 Gy was delivered on the second day of treatment. (A) Tumor growth of mice treated with radiation and the combination of AF (3 mg/kg) and BSO (25 mg/kg). (B) Survival curves of mice euthanized at diameter of $15 \mathrm{~mm}$. (C) Assessment of toxicity by body weight loss. 
(Molecular Devices, Sunnyvale, CA, USA). Cell viability was determined by dividing the absorbance values of treated cells to that of untreated (control) cells.

\section{Radiation and clonogenic assay}

Clonogenic assay was performed as reported in detail elsewhere [22]. Briefly, confluent cultures in 6-well plates were treated with $\mathrm{AF}$ and/or BSO and irradiated at a dose rate of $2 \mathrm{~Gy} / \mathrm{min}$ on a $6 \mathrm{MV}$ Linac (Elekta, Crowley, UK). To induce hypoxia, treated cultures were placed in a tissue-mimetic culture system (TMCS) for $45 \mathrm{~min}$ at $37^{\circ} \mathrm{C}$ in order to metabolically consume oxygen [22]. Cells were then irradiated at indicated doses, trypsinized and reseeded for colony formation. After 8 days, cultures were fixed with crystal violet and colonies (>50 cells) were counted. Survival fractions (SF) were fitted to the linear quadratic model using GraphPad Prism 5 software (GraphPad Prism Software Inc., La Jolla, CA, USA). Radiosensitization was expressed as an enhancement ratio determined at a SF of 0.1.

\section{Apoptotic assay}

Apoptosis was analyzed by using the double staining with the lipophilic dye Annexin V and 7-amino actinomycin D (7-AAD) (Abcam, Cambridge, UK). Briefly, $0.5 \times 10^{6}$ cells were treated with $\mathrm{AF}$ for $2 \mathrm{~h}$, harvested by trypsin, washed twice with PBS and resuspended in $100 \mu \mathrm{l}$. Thereafter, $2.5 \mu \mathrm{l}$ Annexin V-FITC and $5 \mu \mathrm{l}$ 7-AAD were added to the cell suspensions and incubated for $20 \mathrm{~min}$ at room temperature in the dark. Early apoptotic cells (Annexin V-positive, 7-AAD-negative), necrotic/late apoptotic cells (double-positive), and living cells (doublenegative) were determined by flow cytometry (BD LSR Fortsessa, BD Bioscience, Franklin Lakes, USA).

\section{Double-strand DNA breaks}

DNA damage following irradiation at 8 Gy was determined by the extent of phosphorylation of the histone protein $\gamma \mathrm{H} 2 \mathrm{AX}$. Cells were treated with $\mathrm{AF}$ $(7.5 \mu \mathrm{M})$ for $2 \mathrm{~h}$, fixed in a buffer (Miltenyi biotec, Leiden, Netherlands) for $15 \mathrm{~min}$ at room temperature and permeabilized for $20 \mathrm{~min}$ in $90 \%$ methanol at $-20^{\circ} \mathrm{C}$. Next, cells were incubated with $0.1 \mu \mathrm{g} \gamma \mathrm{H} 2 \mathrm{AX}$ antibody (Abcam, Cambridge, UK) for $40 \mathrm{~min}$ at $4{ }^{\circ} \mathrm{C}$ and analyzed by flow cytometry.

\section{ROS production}

The intracellular level of ROS was detected using 5-(6)-chloromethyl-2', 7'-dichlorodihydro-fluorescein diacetate (CM- $\left.\mathrm{H}^{2} \mathrm{DCFDA}\right)$, an oxidation-sensitive fluorescent probe (Abcam, Cambridge, UK). Briefly, cells were treated with $\mathrm{AF}$ for $2 \mathrm{~h}$, stained with $5 \mu \mathrm{M}$
$\mathrm{CM}-\mathrm{H}^{2} \mathrm{DCFDA}$ at $37^{\circ} \mathrm{C}$ for $30 \mathrm{~min}$ and analyzed by flow cytometry.

\section{TrxR activity}

TrxR activity was measured by using a commercial kit (Sigma-Aldrich, Antwerp, Belgium) according to the manufacturer's instructions. In this assay, TrxR catalyzes the reduction of 5, 5-dithiobis (2-nitrobenzoic) acid (DTNB) to 5-thio-2-nitrobenzoic acid, which generates a strong yellow color. Briefly, cells were treated with AF, lysed with CelLytic Buffer (SigmaAldrich, Antwerp, Belgium) and disrupted by sonication for 1min. Afterwards, $180 \mu \mathrm{l}$ of TE buffer containing DTNB and NADPH was added. The linear increase in absorbance at $412 \mathrm{~nm}$ was measured during 30 min using a spectrophotometer (Molecular Devices, Sunnyvale, CA, USA). TrxR activity was calculated as a percentage of enzyme activity to that of DMSO-treated samples.

\section{GSH assay}

GSH levels were measured with a commercial GSH assay kit (Sanbio, Belgium). Briefly, cells were treated with BSO, washed twice with PBS and resuspended in cold MES buffer. Next, cells were lysed by sonication for $1 \mathrm{~min}$, centrifuged at $10000 \mathrm{rpm}$ for $15 \mathrm{~min}$ at $4^{\circ} \mathrm{C}$ and finally deproteinized by phosphoric acid. Afterwards, $50 \mu \mathrm{l}$ of the collected supernatant was added to $150 \mu \mathrm{l}$ assay cocktail, and absorbance was measured at $405 \mathrm{~nm}$ using a spectrophotometer during 30 minutes with fiveminute intervals.

\section{Oxygen consumption rates}

Oxygen consumption rates were determined using a Seahorse XF96 analyzer (Seahorse Biosciences, North Billerica, MA, USA) as previously reported [55]. Briefly, $1.5 \times 10^{5}$ cells were seeded in 96-well plates and $24 \mathrm{~h}$ later were treated with AF for $2 \mathrm{~h}$. Afterwards, cultures were equilibrated in unbuffered DMEM with glutamine and glucose at $37^{\circ} \mathrm{C}$ in a $\mathrm{CO}^{2}$-free incubator and processed for measurements. To extract detailed information on the electron transport chain in mitochondria, the standard sequence of specific inhibitors consisting of oligomycin, FCCP, rotenone and antimycin A was used.

\section{Mitochondrial membrane potential}

Mitochondrial membrane potential was measured using a potential-dependent positively-charged red-orange dye tetramethylrhodamine ethyl ester (Abcam, Cambridge, UK), which accumulates in active mitochondria due to their relative negative charge. Briefly, after treatment with AF for $2 \mathrm{~h}$, cells were stained with $400 \mathrm{nM}$ dye at $37^{\circ} \mathrm{C}$ for $30 \mathrm{~min}$ and analyzed by flow cytometry. 


\section{Mouse tumor model}

$\mathrm{BALB} / \mathrm{c}$ mice were inoculated intramuscularly into the left hind limb with 4T1 or EMT6 cells $\left(0.5 \times 10^{6}\right)$ and 4 days later randomized with 6 mice/group, $\mathrm{AF}(3 \mathrm{mg} / \mathrm{kg})$ and $/$ or BSO $(25 \mathrm{mg} / \mathrm{kg})$ were administrated subcutaneously from day 6 to 10 and day 13 to 17 . Tumors were irradiated with $15 \mathrm{~Gy}$ on day 5 at a dose rate of $2 \mathrm{~Gy} / \mathrm{min}$ on a 6 MV Linac (Elekta, Crowley, UK). The tumor volume was calculated using the formula $\mathrm{V}=\left(\mathrm{L}^{*} \mathrm{~W}^{2}\right) * 0.5$, where $\mathrm{V}=$ volume, $\mathrm{L}=$ length, and $\mathrm{W}=$ width.

\section{Statistics}

All assays were repeated at least three times. A one-way ANOVA followed by a Bonferonni's multiple comparison tests was performed using GraphPad Prism 5. Data are expressed as mean with corresponding standard deviations. The number of asterisks in the figures indicates the level of statistical significance as follow: ${ }^{*} p<0.05$, ${ }^{* *} p<0.01, * * * p<0.001, * * * * p<0.0001$.

\section{ACKNOWLEDGMENTS AND FUNDING}

This work was supported by grants from the VLK (Vlaamse Ligategen Kanker) and RCT (Reliable Cancer Therapies). HW is funded by the CSC (China Scholarship Council). ID is funded by the IWT (agentschap voor Innovatie door Wetenschap en Technologie). The study sponsors had no involvement in study design, in the collection, analysis and interpretation of the data, not in the writing of the manuscript and the decision to submit the manuscript for publication.

\section{CONFLICTS OF INTEREST}

The authors declare no potential conflicts of interest.

\section{REFERENCES}

1. Trachootham D, Alexandre J, Huang P. Targeting cancer cells by ROS-mediated mechanisms: a radical therapeutic approach? Nat Rev Drug Discov. 2009; 8:579-591.

2. Iwasawa S, Yamano Y, Takiguchi Y, Tanzawa H, Tatsumi K, Uzawa K. Upregulation of thioredoxin reductase 1 in human oral squamous cell carcinoma. Oncol Rep. 2011; 25:637-644.

3. Kakolyris S, Giatromanolaki A, Koukourakis M, Powis G, Souglakos J, Sivridis E, Georgoulias V, Gatter KC, Harris AL. Thioredoxin expression is associated with lymph node status and prognosis in early operable non-small cell lung cancer. Clin Cancer Res. 2001; 7:3087-3091.

4. Porporato PE, Payen VL, Perez-Escuredo J, De Saedeleer CJ, Danhier P, Copetti T, Dhup S, Tardy M, Vazeille T, Bouzin C, Feron O, Michiels C, Gallez B, et al.
A mitochondrial switch promotes tumor metastasis. Cell Rep. 2014; 8:754-766.

5. Kim SY, Kim SJ, Kim BJ, Rah SY, Chung SM, Im MJ, Kim UH. Doxorubicin-induced reactive oxygen species generation and intracellular $\mathrm{Ca} 2+$ increase are reciprocally modulated in rat cardiomyocytes. Exp Mol Med. 2006; 38:535-545.

6. Yamamori T, Yasui H, Yamazumi M, Wada Y, Nakamura Y, Nakamura $H$, Inanami $O$. Ionizing radiation induces mitochondrial reactive oxygen species production accompanied by upregulation of mitochondrial electron transport chain function and mitochondrial content under control of the cell cycle checkpoint. Free Radic Biol Med. 2012; 53:260-270.

7. Sena LA, Chandel NS. Physiological roles of mitochondrial reactive oxygen species. Mol cell. 2012; 48:158-167.

8. Griffith OW. Mechanism of action, metabolism, and toxicity of buthionine sulfoximine and its higher homologs, potent inhibitors of glutathione synthesis. J Biol Chem. 1982; 257:13704-13712.

9. Davison K, Cote S, Mader S, Miller WH. Glutathione depletion overcomes resistance to arsenic trioxide in arsenic-resistant cell lines. Leukemia. 2003; 17:931-940.

10. Leung SW, Mitchell JB, al-Nabulsi I, Friedman N, Newsome J, Belldegrun A, Kasid U. Effect of L-buthionine sulfoximine on the radiation response of human renal carcinoma cell lines. Cancer. 1993; 71:2276-2285.

11. Fiskus W, Saba N, Shen M, Ghias M, Liu J, Gupta SD, Chauhan L, Rao R, Gunewardena S, Schorno K, Austin CP, Maddocks K, Byrd J, et al. Auranofin induces lethal oxidative and endoplasmic reticulum stress and exerts potent preclinical activity against chronic lymphocytic leukemia. Cancer Res. 2014; 74:2520-2532.

12. Zou P, Chen M, Ji J, Chen W, Chen X, Ying S, Zhang J, Zhang Z, Liu Z, Yang S, Liang G. Auranofin induces apoptosis by ROS-mediated ER stress and mitochondrial dysfunction and displayed synergistic lethality with piperlongumine in gastric cancer. Oncotarget. 2015; 6:36505-21. doi: 10.18632/oncotarget.5364.

13. Topkas E, Cai N, Cumming A, Hazar-Rethinam M, Gannon OM, Burgess M, Saunders NA, Endo-Munoz L. Auranofin is a potent suppressor of osteosarcoma metastasis. Oncotarget. 2016; 7:831-44. doi: 10.18632/oncotarget.5704.

14. Raninga PV, Di Trapani G, Vuckovic S, Bhatia M, Tonissen KF. Inhibition of thioredoxin 1 leads to apoptosis in drug-resistant multiple myeloma. Oncotarget. 2015; 6:15410-24. doi: 10.18632/oncotarget.3795.

15. Chen X, Shi X, Zhao C, Li X, Lan X, Liu S, Huang H, Liu N, Liao S, Zang D, Song W, Liu Q, Carter BZ, et al. Anti-rheumatic agent auranofin induced apoptosis in chronic myeloid leukemia cells resistant to imatinib through both Bcr/ Abl-dependent and -independent mechanisms. Oncotarget. 2014; 5:9118-32. doi: 10.18632/oncotarget.2361. 
16. Fan C, Zheng W, Fu X, Li X, Wong YS, Chen T. Enhancement of auranofin-induced lung cancer cell apoptosis by selenocystine, a natural inhibitor of TrxR1 in vitro and in vivo. Cell Death Dis. 2014; 5:e1191.

17. Gandin V, Fernandes AP, Rigobello MP, Dani B, Sorrentino F, Tisato F, Bjornstedt M, Bindoli A, Sturaro A, Rella R, Marzano C. Cancer cell death induced by phosphine gold(I) compounds targeting thioredoxin reductase. Biochem Pharmacol. 2010; 79:90-101.

18. Liu N, Li X, Huang H, Zhao C, Liao S, Yang C, Liu S, Song W, Lu X, Lan X, Chen X, Yi S, Xu L, et al. Clinically used antirheumatic agent auranofin is a proteasomal deubiquitinase inhibitor and inhibits tumor growth. Oncotarget. 2014; 5:5453-71. doi: 10.18632/oncotarget.2113.

19. Marzano C, Gandin V, Folda A, Scutari G, Bindoli A, Rigobello MP. Inhibition of thioredoxin reductase by auranofin induces apoptosis in cisplatin-resistant human ovarian cancer cells. Free Radic Biol Med. 2007; 42:872-881.

20. Rodman SN, Spence JM, Ronnfeldt TJ, Zhu Y, Solst SR, O'Neill RA, Allen BG, Guan X, Spitz DR, Fath MA. Enhancement of Radiation Response in Breast Cancer Stem Cells by Inhibition of Thioredoxin- and GlutathioneDependent Metabolism. Radiat Res. 2016; 186:385-395.

21. Leonard W, Dufait I, Schwarze JK, Law K, Engels B, Jiang H, Van den Berge D, Gevaert T, Storme G, Verovski V, Breckpot K, De Ridder M. Myeloid-derived suppressor cells reveal radioprotective properties through arginaseinduced 1-arginine depletion. Radiother Oncol. 2016; 119:291-299.

22. Jiang H, De Ridder M, Verovski VN, Sonveaux P, Jordan BF, Law K, Monsaert C, Van den Berge DL, Verellen D, Feron O, Gallez B, Storme GA. Activated macrophages as a novel determinant of tumor cell radioresponse: the role of nitric oxide-mediated inhibition of cellular respiration and oxygen sparing. Int J Radiat Oncol Biol Phys. 2010; 76:1520-1527.

23. Gromer S, Arscott LD, Williams CH Jr, Schirmer RH, Becker K. Human placenta thioredoxin reductase. Isolation of the selenoenzyme, steady state kinetics, and inhibition by therapeutic gold compounds. J Biol Chem. 1998; 273:20096-20101.

24. Saccoccia F, Angelucci F, Boumis G, Brunori M, Miele AE, Williams DL, Bellelli A. On the mechanism and rate of gold incorporation into thiol-dependent flavoreductases. J Inorg Biochem. 2012; 108:105-111.

25. Reliene R, Pollard JM, Sobol Z, Trouiller B, Gatti RA, Schiestl RH. N-acetyl cysteine protects against ionizing radiation-induced DNA damage but not against cell killing in yeast and mammals. Mutat Res. 2009; 665:37-43.

26. Diepart C, Karroum O, Magat J, Feron O, Verrax J, Calderon PB, Gregoire V, Leveque P, Stockis J, Dauguet N, Jordan BF, Gallez B. Arsenic trioxide treatment decreases the oxygen consumption rate of tumor cells and radiosensitizes solid tumors. Cancer Res. 2012; 72:482-490.

27. McQuaid HN, Muir MF, Taggart LE, McMahon SJ, Coulter JA, Hyland WB, Jain S, Butterworth KT, Schettino G,
Prise KM, Hirst DG, Botchway SW, Currell FJ. Imaging and radiation effects of gold nanoparticles in tumour cells. Sci Rep. 2016; 6:19442.

28. Shaw IC. Gold-based therapeutic agents. Chem Rev. 1999; 99:2589-2600.

29. Gao F, Yi J, Yuan JQ, Shi GY, Tang XM. The cell cycle related apoptotic susceptibility to arsenic trioxide is associated with the level of reactive oxygen species. Cell Res. 2004; 14:81-85.

30. Jain S, Coulter JA, Hounsell AR, Butterworth KT, McMahon SJ, Hyland WB, Muir MF, Dickson GR, Prise KM, Currell FJ, O’Sullivan JM, Hirst DG. Cellspecific radiosensitization by gold nanoparticles at megavoltage radiation energies. Int J Radiat Oncol Biol Phys. 2011; 79:531-539.

31. Craig S, Gao L, Lee I, Gray T, Berdis AJ. Gold-containing indoles as anticancer agents that potentiate the cytotoxic effects of ionizing radiation. J Med Chem. 2012; 55:2437-2451.

32. Selenius M, Hedman M, Brodin D, Gandin V, Rigobello MP, Flygare J, Marzano C, Bindoli A, Brodin O, Bjornstedt M, Fernandes AP. Effects of redox modulation by inhibition of thioredoxin reductase on radiosensitivity and gene expression. J Cell Mol Med. 2012; 16:1593-1605.

33. Trachootham D, Alexandre J, Huang P. Targeting cancer cells by ROS-mediated mechanisms: a radical therapeutic approach? Nat Rev Drug Discov. 2009; 8:579-591.

34. Han S, Kim K, Kim H, Kwon J, Lee YH, Lee CK, Song Y, Lee SJ, Ha N, Kim K. Auranofin inhibits overproduction of pro-inflammatory cytokines, cyclooxygenase expression and PGE2 production in macrophages. Arch Pharm Res. 2008; 31:67-74.

35. Navarro M, Fraile G, Velasquez M, Gonzalez E, Escalona J, Ilanjian R, Abad MJ, Taylor P. Effect of a goldchloroquine complex on inflammation-related leukocyte functions and cell viability. Comparison with auranofin. Arzneimittelforschung. 2006; 56:826-833.

36. Kalluri R. The biology and function of fibroblasts in cancer. Nat Rev Cancer. 2016; 16:582-598.

37. Dufait I, Schwarze JK, Liechtenstein T, Leonard W, Jiang H, Escors D, De Ridder M, Breckpot K. Ex vivo generation of myeloid-derived suppressor cells that model the tumor immunosuppressive environment in colorectal cancer. Oncotarget. 2015; 6:12369-82. doi: 10.18632/oncotarget.3682.

38. Bronte V, Zanovello P. Regulation of immune responses by L-arginine metabolism. Nat Rev Immunol. 2005; 5:641-654.

39. Templeton AJ, McNamara MG, Seruga B, Vera-Badillo FE, Aneja P, Ocana A, Leibowitz-Amit R, Sonpavde G, Knox JJ, Tran B, Tannock IF, Amir E. Prognostic role of neutrophilto-lymphocyte ratio in solid tumors: a systematic review and meta-analysis. J Natl Cancer Inst. 2014; 106:dju124.

40. Colotta F, Allavena P, Sica A, Garlanda C, Mantovani A. Cancerrelated inflammation, the seventh hallmark of cancer: links to genetic instability. Carcinogenesis. 2009; 30:1073-1081.

41. Senovilla L, Vacchelli E, Galon J, Adjemian S, Eggermont A, Fridman WH, Sautes-Fridman C, Ma Y, 
Tartour E, Zitvogel L, Kroemer G, Galluzzi L. Trial watch: Prognostic and predictive value of the immune infiltrate in cancer. Oncoimmunology. 2012; 1:1323-1343.

42. Sermeus A, Leonard W, Engels B, De Ridder M. Advances in radiotherapy and targeted therapies for rectal cancer. World J Gastroenterol. 2014; 20:1-5.

43. Harris IS, Treloar AE, Inoue S, Sasaki M, Gorrini C, Lee KC, Yung KY, Brenner D, Knobbe-Thomsen CB, Cox MA, Elia A, Berger T, Cescon DW, et al. Glutathione and thioredoxin antioxidant pathways synergize to drive cancer initiation and progression. Cancer cell. 2015; 27:211-222.

44. Van Riel PL, Gribnau FW, Van de Putte LB, Arts CW, Van Aernsbergen A. Serum gold concentrations during treatment with auranofin. Clin Rheumatol. 1987; 6:50-54.

45. Smart DK, Ortiz KL, Mattson D, Bradbury CM, Bisht KS, Sieck LK, Brechbiel MW, Gius D. Thioredoxin reductase as a potential molecular target for anticancer agents that induce oxidative stress. Cancer Res. 2004; 64:6716-6724.

46. Javvadi P, Hertan L, Kosoff R, Datta T, Kolev J, Mick R, Tuttle SW, Koumenis C. Thioredoxin reductase-1 mediates curcumin-induced radiosensitization of squamous carcinoma cells. Cancer Res. 2010; 70:1941-1950.

47. Liang YW, Zheng J, Li X, Zheng W, Chen T. Selenadiazole derivatives as potent thioredoxin reductase inhibitors that enhance the radiosensitivity of cancer cells. Eur J Med Chem. 2014; 84:335-342.

48. Polet F, Corbet C, Pinto A, Rubio LI, Martherus R, Bol V, Drozak X, Grégoire V, Riant O, Feron O. Reducing the serine availability complements the inhibition of the glutamine metabolism to block leukemia cell growth. Oncotarget. 2016; 7:1765-76. doi: 10.18632/oncotarget.6426.

49. Young SW, Qing F, Harriman A, Sessler JL, Dow WC, Mody TD, Hemmi GW, Hao Y, Miller RA. Gadolinium(III) texaphyrin: a tumor selective radiation sensitizer that is detectable by MRI. Proc Natl Acad Sci USA. 1996; 93:6610-6615.

50. Du Y, Zhang H, Lu J, Holmgren A. Glutathione and glutaredoxin act as a backup of human thioredoxin reductase 1 to reduce thioredoxin 1 preventing cell death by aurothioglucose. J Biol Chem. 2012; 287:38210-38219.

51. Roh JL, Jang H, Kim EH, Shin D. Targeting of the Glutathione, Thioredoxin, and Nrf2 Antioxidant Systems in Head and Neck Cancer. Antioxid Redox Signal. 2016.

52. Li L, Fath MA, Scarbrough PM, Watson WH, Spitz DR. Combined inhibition of glycolysis, the pentose cycle, and thioredoxin metabolism selectively increases cytotoxicity and oxidative stress in human breast and prostate cancer. Redox Biol. 2015; 4:127-135.

53. Engels B, Platteaux N, Van den Begin R, Gevaert T, Sermeus A, Storme G, Verellen D, De Ridder M. Preoperative intensity-modulated and image-guided radiotherapy with a simultaneous integrated boost in locally advanced rectal cancer: report on late toxicity and outcome. Radiother Oncol. 2014; 110:155-159.

54. Engels B, Tournel K, Everaert H, Hoorens A, Sermeus A, Christian N, Storme G, Verellen D, De Ridder M. Phase II study of preoperative helical tomotherapy with a simultaneous integrated boost for rectal cancer. Int J Radiat Oncol Biol Phys. 2012; 83:142-148.

55. Polet F, Corbet C, Pinto A, Rubio LI, Martherus R, Bol V, Drozak X, Gregoire V, Riant O, Feron O. Reducing the serine availability complements the inhibition of the glutamine metabolism to block leukemia cell growth. Oncotarget. 2016; 7:1765-1776. doi: 10.18632/ oncotarget. 6426. 